\title{
Prognostic Value of Inflammation-based Prognostic Scores in Patients with Colorectal Cancer
}

\author{
João Pedro Lima Afonso ${ }^{1}$ Ana Pereira ${ }^{2}$ Joaquim Costa Pereira ${ }^{3}$ Sandra F. Martins ${ }^{1,3,4}$
}

${ }^{1}$ Life and Health Sciences Research Institute (ICVS), Escola de Medicina, Universidade do Minho, Braga, Portugal

2 Department of General Surgery, Hospital de Braga, Braga, Portugal

${ }^{3}$ Coloproctology Unit, Department of General Surgery, Hospital de Braga, Braga, Portugal

${ }^{4}$ Life and Health Sciences Research Institute/Biomaterials, Biodegradables and Biomimetics (ICVS/3B's)- Associate Laboratory, Braga/Guimarães, Braga, Portugal

J Coloproctol 2021;41(4):393-405.

\begin{abstract}
Address for correspondence Sandra F. Martins, MD, PhD, Instituto de Investigação em Ciências da Vida e Saúde (ICVS), Escola de Medicina, Universidade do Minho, Campus de Gualtar, Rua da Universidade, 4710-057 Braga, Portugal (e-mail: sandramartins@med.uminho.pt).
\end{abstract}

\section{Abstract \\ Keywords \\ - colorectal cancer \\ - scores of systemic inflammatory markers \\ - NLR \\ - GPS \\ - CRP}

Background Anatomopathological staging is the primary method to determine the prognosis of patients with colorectal carcinoma (CRC). However, new tools have been developed that can complement it, such as the analysis of the elevation of systemic inflammatory markers.

Objective To evaluate the impact of the elevation of scores based on inflammatory markers (the neutrophil-to-lymphocyte ratio [NLR], the Glasgow Prognostic Score [GPS], and isolated C-reactive protein [CRP]) in the prognosis of patients diagnosed with CRC and submitted to potentially curative surgery in Hospital de Braga, Portugal, between January 1st, 2005, and December 31st, 2010.

Methods A retrospective analysis of the data of $\mathbf{4 2 6}$ patients was performed, with a collection of several clinico-pathological variables, as well as the levels of lymphocytes, neutrophils, albumin and CRP, in the pre- and postoperative periods, to apply the different scores to the sample.

Results From the analysis of the survival curves, we concluded that patients with increased NLR in the pre- and postoperative periods present a lower cancer-related survival than patients with normal NLR (preoperative period: 93.7 versus 122 months; $\mathrm{p}<0.001$; postoperative period: 112 versus 131 months; $\mathrm{p}=0.002$ ). Patients with increased NLR in the pre- and postoperative periods also had a lower disease-free survival (preoperative period: 88.0 versus 122 months; $p<0.001$; postoperative period: 111 versus 132 months; $p=0.002$ ). In addition, increased pre- and postoperative NLR was associated with a higher risk of death due to CRC (preoperatively: hazard ratio $[H R]=2.25 ; p<0.001$; postoperatively: $H R=2.18 ; p=0.003)$. However, the received

September 12, 2020

accepted

January 18, 2021
DOI https://doi.org/

$10.1055 / \mathrm{s}-0041-1735458$. ISSN 2237-9363. (c) 2021. Sociedade Brasileira de Coloproctologia. All rights reserved.

This is an open access article published by Thieme under the terms of the Creative Commons Attribution-NonDerivative-NonCommercial-License, permitting copying and reproduction so long as the original work is given appropriate credit. Contents may not be used for commercial purposes, or adapted, remixed, transformed or built upon. (https://creativecommons.org/ licenses/by-nc-nd/4.0/)

Thieme Revinter Publicações Ltda., Rua do Matoso 170, Rio de Janeiro, RJ, CEP 20270-135, Brazil 
multivariate analysis shows that only postoperative NLR (ajusted HR $=2.66 ; \mathrm{p}=0.002$ ) does so independently of the remaining variables.

Conclusion Regarding the scores applied to the sample, the NLR was the one that most consistently related to the prognosis of the patients. However, it would be useful to develop a prospective study that could confirm this relationship.

\section{Introduction}

Recently, the impact of elevated systemic inflammatory markers such as the Glasgow Prognostic Score (GPS), the neutrophil-to-lymphocyte ratio (NLR) or isolated C-Reactive Protein (CRP) on the prognosis of different oncological diseases, namely in colorectal carcinoma (CRC) has been studied and recognized. $^{1-7}$

The GPS consists of the combination of CRP values and serum albumin, and its increase may reflect a systemic inflammatory response state associated with the neoplastic process. Hypoalbuminemia can also be related to cachexia present in advanced stages of the disease. ${ }^{8,9}$

The increase in the NLR has been associated with a worse prognosis not only in several oncological diseases, but also in cases of cardiovascular diseases. The rationale that supports this association is also based on the fact that a greater systemic inflammatory response, often subclinical, may be related to a worse prognosis. ${ }^{10}$

Given these assumptions, it is extremely important to understand the relationship between these scales and the prognosis of patients operated due to CRC in order to be able to more quickly and easily establish the prognosis of patients and guide them in a more personalized and effective manner.

\section{Materials and Methods}

The present is an observational, retrospective and descriptive study.

The study population consisted of all patients with a diagnosis of CRC who underwent surgical treatment between January 1st, 2005, and December 31st, 2010. A non-probabilistic convenience sample was developed, applying several inclusion and exclusion criteria to the target population. Inclusion criteria: patients with postoperative histological diagnosis of colorectal adenocarcinoma, who underwent surgical resection at Hospital de Braga between January 1st, 2005, and December 31st, 2010. Exclusion criteria: patients undergoing surgical resection with palliative intent; patients undergoing urgent surgical resection; patients in whom it was not possible to assess the value of inflammatory parameters; patients with no result of histological staging; and patients who died in the postoperative period (30 days or less after surgery).

For each patient, we collected data on: gender; age at the date of surgery; personal history of neoplasia; family history of CRC; duration of the symptoms; tumor location; macroscopic aspect of the tumor; preoperative levels of carcinoembryonic antigen (CEA); tumor dimension; histological type; tumor staging; levels of lymphocytes, neutrophils, albumin and pre- and postoperative CRP; date of death; and date of onset of local recurrence and distant progression of the disease.

Cancer-related survival was defined as the period in months from the date of the first surgery to the date of cancer-related death.

Disease-free time was defined as the period from the first surgery until the diagnosis of local recurrence or distant progression of the disease.

As the present is a retrospective study, it was not possible to guarantee that the analyses had been carried out at the same pre- and postoperative periods. In order to minimize the impact of this situation, the data was collected at a interval-time within a maximum period of 15 days before and 3 days after surgery.

The statistical analysis was performed using the Statistical Package for the Social Sciences (IBM SPSS Statistics for Windows, IBM Corp., Armonk, NY, US) software, version 22.

For all tests performed, statistically significant results were defined as $\mathrm{p}<0.05$.

Initially, a descriptive analysis of the many variables collected was carried out, in order to characterize the sample under study. Then, three scales were chosen to characterize the systemic proinflammatory state of the patients: the NLR, the GPS, and elevation of isolated CRP. Each of the scales was applied to patients in the pre- and postoperative periods.

With regard to the NLR, which is the ratio between the absolute levels of neutrophils and lymphocytes, values above 5 eere considered high, according to a study by Urrejola et al. ${ }^{11}$

The GPS, which results from the combination of the CRP and albumin levels, was categorized into 3 groups $(0,1$ and 2 ), depending on whether they had 0 altered values, only 1 or 2 respectively, as can be seen in -Table $\mathbf{1}$. For the calculation of this scale, CRP levels higher than $1 \mathrm{mg} / \mathrm{dl}$ and albumin lower than $3.5 \mathrm{~g} / \mathrm{dl}$ were defined as altered, since these were the reference values of the laboratory responsible for the analytical evaluation of all patients.

Table 1 Categorization of the different groups on the Glasgow Prognostic Score (GPS)

\begin{tabular}{|l|l|}
\hline $\mathrm{GPS}=0$ & $\mathrm{CRP} \leq 1 \mathrm{mg} / \mathrm{dl}$ and albumin $\geq 3.5 \mathrm{~g} / \mathrm{dl}$ \\
\hline $\mathrm{GPS}=1$ & $\mathrm{CRP}>1 \mathrm{mg} / \mathrm{dl}$ or albumin $<3.5 \mathrm{~g} / \mathrm{dl}$ \\
\hline $\mathrm{GPS}=2$ & $\mathrm{CRP}>1 \mathrm{mg} / \mathrm{dl}$ and albumin $<3.5 \mathrm{~g} / \mathrm{dl}$ \\
\hline
\end{tabular}

Abbreviation: CRP, C-reactive protein. 
Finally, levels of isolated CRP was defined as increased when higher than $1 \mathrm{mg} / \mathrm{dl}$, for the same reason mentioned for the calculation of the GPS.

In order to determine the correlation between the different scales and the clinico-pathological characteristics of the patients, crosstabs were performed, and the interdependence of the variables was analyzed using the Fisher exact test whenever the number of cells with a value lower than 5 was greater than $20 \%$ of the total cells, and the Pearson Chisquared $\left(\chi^{2}\right)$ test when it was lower than $20 \%$. As a measure of effect size, the Phi coefficient $(\Phi)$ was used for $2 \times 2$ tables, as well as the Cramer V for larger tables. For both coefficients, small, medium or large effects were considered for values close to $0.1,0.3$ and 0.5 respectively. For the variables that showed a statistically significant correlation, adjusted standardized residuals were evaluated, and residuals with an absolute value greater than 1.96 were considered as statistically significant, in order to determine the contribution of each cell to the significance of the test and thus determine the direction of the association.

In order to determine the impact of the elevation of the different scales on the outcome of the patients, an attempt was made to compare the time from surgery to the occurrence of two events: death by CRC or recurrence of the disease. For this purpose, Kaplan-Meier survival curves were made, in order to check if there were differences between the groups with increased and normal inflammatory parameters in relation to the survival time and diseasefree time. The comparison between the survival curves of the different groups was performed using the log-rank test.

Finally, a univariate analysis of the impact of all variables under study on the patients' survival time was performed, followed by a multivariate analysis using only those that, in the univariate analysis, significantly influenced the survival time. For this evaluation, the Cox proportional-hazards model was used.

The present study was carried out in accordance with the principles of the Declaration of Helsinki, the Convention on Human Rights and Biomedicine, the guidelines of the Council for International Organizations of Medical Sciences, and the Guide to Good Clinical Practice, and was approved by the Ethics Subcommittee on the Life and Health Sciences of Universidade do Minho (SECVS-063/2017) and by the Health Ethics Committee of Hospital de Braga (HB-70/2017).

\section{Results}

After applying the exclusion criteria, a sample of 426 patients was obtained.

The clinico-pathological characteristics and the distribution of the sample in relation to the different scales are described in -Tables $\mathbf{2}$ and $\mathbf{3}$ respectively.

Of the studied patients, $32.8 \%$ died due to CRC. The remaining $67.2 \%$ are either still alive, or died of other causes, or were lost to follow-up. The average cancer-related survival of the patients was of about 117 months.

The cancer-related survival curve obtained by the KaplanMeier method is shown in -Figure $\mathbf{1}$.
Table 2 Clinico-pathological characteristics of the sample

\begin{tabular}{|c|c|}
\hline & n (\%) \\
\hline \multicolumn{2}{|l|}{ Gender } \\
\hline Male & $260(61.0)$ \\
\hline Female & $166(39.0)$ \\
\hline \multicolumn{2}{|l|}{ Age (years) } \\
\hline$<45$ & $16(3.8)$ \\
\hline$>45$ & $410(96.2)$ \\
\hline \multicolumn{2}{|l|}{ Previous neoplasia } \\
\hline Present & $56(13.1)$ \\
\hline Absent & $370(86.9)$ \\
\hline \multicolumn{2}{|c|}{ Family history of colorectal canrcinoma } \\
\hline Present & $3(7.7)$ \\
\hline Absent & $359(83.3)$ \\
\hline Unknown & $34(8.0)$ \\
\hline \multicolumn{2}{|l|}{ Time with symptoms (months) } \\
\hline$<6$ & $287(67.4)$ \\
\hline$>6$ & $59(13.8)$ \\
\hline Asymptomatic & $80(18.8)$ \\
\hline \multicolumn{2}{|l|}{ Location } \\
\hline Right colon & $99(31.7)$ \\
\hline Left colon & $213(68.3)$ \\
\hline Rectum & $114(26.8)$ \\
\hline \multicolumn{2}{|l|}{ Macroscopic appearance } \\
\hline Polypoid & $222(52.1)$ \\
\hline Ulcerated & $106(24.9)$ \\
\hline Infiltrative & $34(8.0)$ \\
\hline Exophytic & $29(6.8)$ \\
\hline Indeterminate & $35(8.2)$ \\
\hline \multicolumn{2}{|l|}{ Carcinoembryonic antigen (ng/ml) } \\
\hline$\leq 10$ & $307(72.1)$ \\
\hline$>10$ & $52(12.2)$ \\
\hline Indeterminate & $67(15.7)$ \\
\hline \multicolumn{2}{|l|}{ Tumor size $(\mathrm{cm})$} \\
\hline$\leq 4.5$ & 255 (59.9) \\
\hline$>4.5$ & $154(36.1)$ \\
\hline Indeterminate & $17(4.0)$ \\
\hline \multicolumn{2}{|l|}{ Histological type } \\
\hline Adenocarcinoma & $379(89.0)$ \\
\hline Mucinous adenocarcinoma & $44(10.3)$ \\
\hline Signet-ring cell adenocarcinoma & $3(0.7)$ \\
\hline \multicolumn{2}{|l|}{ Stage } \\
\hline 1 & $79(18.5)$ \\
\hline II & $187(43.9)$ \\
\hline III & 160 (37.6) \\
\hline
\end{tabular}

Of the studied patients, $23.2 \%$ had local or distant recurrence of the disease. The average disease-free time was of about 114 months. 
Table 3 Distribution of patients in relation to the scales of systemic inflammatory markers

\begin{tabular}{|l|l|l|}
\hline & $\begin{array}{l}\text { Preoperative } \\
\text { period }\end{array}$ & $\begin{array}{l}\text { Postoperative } \\
\text { period }\end{array}$ \\
\hline Neutrophil-to-lymphocyte ratio & & \\
\hline Normal $(\leq 5)$ & 282 & 104 \\
\hline Increased $(>5)$ & 75 & 276 \\
\hline Indeterminate & 69 & 46 \\
\hline Glasgow Prognostic Score & & \\
\hline 0 & 5 & 0 \\
\hline 1 & 56 & 14 \\
\hline 2 & 6 & 56 \\
\hline C-reactive protein & & \\
\hline Normal $(\leq 1 \mathrm{mg} / \mathrm{dl})$ & 9 & 1 \\
\hline Increased $(>1 \mathrm{mg} / \mathrm{dl})$ & 90 & 177 \\
\hline Indeterminate & 327 & 248 \\
\hline
\end{tabular}

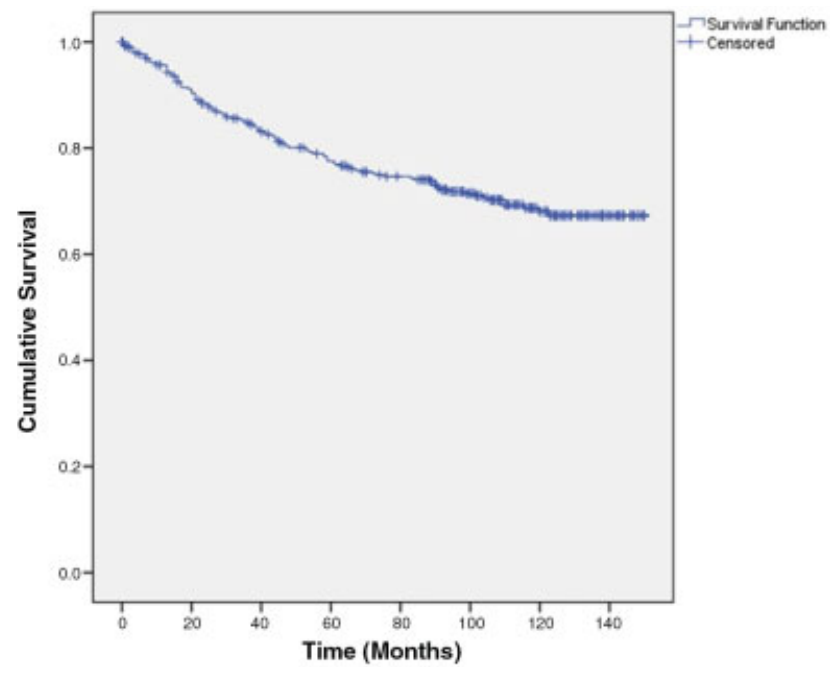

Fig. 1 Kaplan-Meier curve for CRC survival.

The survival curve related to disease-free time obtained by the Kaplan-Meier method is shown in - Figure 2.

\section{Interdependence Analysis}

The assessment of the interdependence of the different clinical variables under study and the scales under analysis is outlined in - Tables 4, 5, 6 .

The evaluation of the crosstab tables regarding the various scores used revealed the existence of a correlation between increased preoperative NLR and the tumor location in the colon/rectum $\left(\chi^{2(1)}=6.251 ; \mathrm{p}=0.012 ; \Phi=-0.132\right)$. The value of $\Phi$ shows that it is a weak association. The analysis of standardized adjusted residuals confirms that colon injury is associated with increased preoperative NLR, as can be seen in - Table 4.

The preoperative NLR also showed a correlation with CEA values $\left(\chi^{2(1)}=7.041 ; \mathrm{p}=0.008 ; \Phi=-0.152\right)$ and more advanced

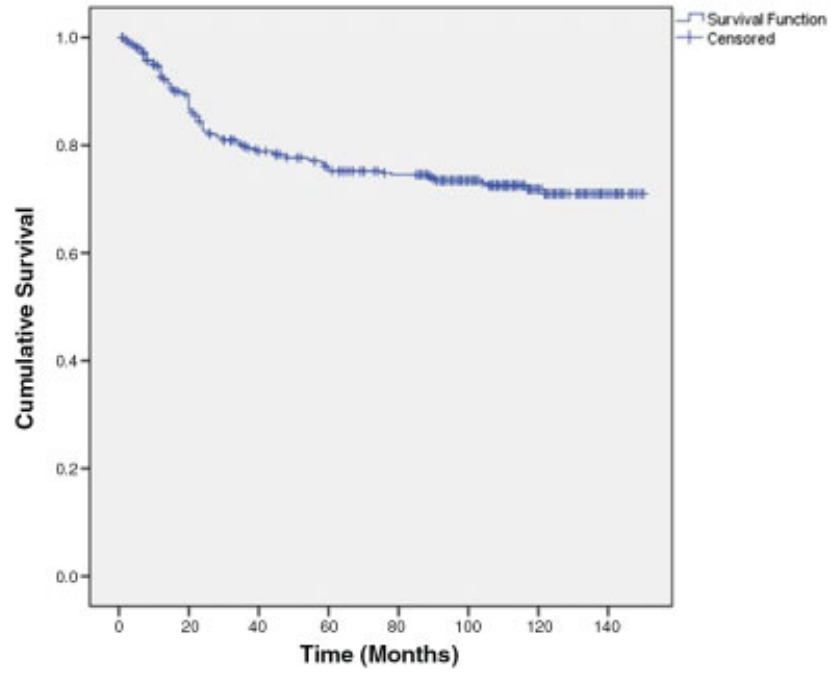

Fig. 2 Kaplan-Meier curve for the disease-free survival of patients.

stages of the disease $\left(\chi^{2(2)}=8.823 ; \mathrm{p}=0.012\right.$; Cramer $\mathrm{V}$ $[\mathrm{V}]=0.157)$. Both situations reflect a weak correlation. The analysis of the standardized adjusted residuals shows that increased NLR is positively related to an increase in the CEA value, and to more advanced stages of the disease, as can be seen in -Table 4.

Regarding the postoperative NLR, its increase is related to the patient's gender $\left(\chi^{2(1)}=4.579 ; \mathrm{p}=0.032 ; \Phi=-0.110\right)$, and, in this case, it was higher NLR in male patients. There is also a correlation with the increase in CEA $\left(\chi^{2(1)}=5.576\right.$; $\mathrm{p}=0.018 ; \Phi=-0.132$ ), with higher values of NLR associated with higher values of CEA. Again, in both cases it is a weak association, as can be seen in - Table 4.

The preoperative GPS was associated with the stage of the disease (Fisher exact test; $\mathrm{p}=0.017$ ), with a lower GPS associated with less advanced stages of the disease, as can be seen in - Table 5 .

The postoperative GPS, on the other hand, was associated with family history (Fisher exact test; $p=0.010$ ), with a higher GPS with the presence of family history. There was also a correlation between the elevation of the preoperative GPS and the occurrence of symptoms prior to diagnosis $\left(\chi^{2(1)}=11.430 ; p<0.001 ; \Phi=0.404\right)$, as can be seen in - Table 5 .

The increase in preoperative CRP, in turn, was associated with the location of the tumor in the colon (Fisher exact test; $\mathrm{p}=0.019$ ) and with its larger dimension (Fisher exact test; $\mathrm{p}=0.026$ ), as can be seen in -Table 6 .

\section{Cancer-Related Survival Assessment}

In order to assess the time of cancer-related survival in relation to the various scales under study, Kaplan-Meier curves were made for each group, and these were compared using the log-rank test.

Patients with increased NLR in the preoperative period had a significantly lower survival than patients with normal NLR (average survival of 122 months and 93.7 months respectively; $\mathrm{p}<0.001$ ), as shown in -Figure $3 \mathbf{A}$ and -Table 7 . 
Prognostic Value of Inflammation-based Prognostic Scores Afonso et al. 397

Table 4 Analysis of interdependence between pre- and postoperative NLR and several clinico-pathological variables

\begin{tabular}{|c|c|c|c|c|c|c|}
\hline & \multicolumn{3}{|c|}{ Preoperative NLR } & \multicolumn{3}{|c|}{ Postoperative NLR } \\
\hline & $\leq 5$ & $>5$ & Statistics & $\leq 5$ & $>5$ & Statistics \\
\hline \multicolumn{7}{|l|}{ Gender } \\
\hline Male & 176 & 49 & $\begin{array}{l}\chi^{2}=0.217 \\
\Phi=-0.25 \\
p=0.641\end{array}$ & 57 & 184 & \multirow[t]{2}{*}{$\begin{array}{l}\chi^{2}=4.579 \\
\Phi=-0.110 \\
p=0.032\end{array}$} \\
\hline Female & 106 & 26 & & 47 & 282 & \\
\hline \multicolumn{7}{|l|}{ Age (years) } \\
\hline$\leq 45$ & 10 & 2 & $\mathrm{p} \leq 0.99$ & 6 & 9 & \multirow{2}{*}{$\begin{array}{l}\chi^{2}=1.253 \\
\Phi=0.057 \\
p=0.263\end{array}$} \\
\hline$>45$ & 272 & 73 & & 98 & 267 & \\
\hline \multicolumn{7}{|l|}{ Previous tumor } \\
\hline Yes & 66 & 9 & $\begin{array}{l}\chi^{2}=0.317 \\
\Phi=-0.30 \\
p=0.573\end{array}$ & 9 & 42 & \multirow[t]{2}{*}{$\begin{array}{l}\chi^{2}=2.801 \\
\Phi=0.086 \\
p=0.094\end{array}$} \\
\hline No & 241 & 41 & & 95 & 234 & \\
\hline \multicolumn{7}{|l|}{ Family history } \\
\hline Yes & 26 & 4 & $p=0.473$ & 6 & 25 & \multirow{2}{*}{$\begin{array}{l}\chi^{2}=0.993 \\
\Phi=0.053 \\
p=0.319\end{array}$} \\
\hline No & 239 & 61 & & 88 & 230 & \\
\hline \multicolumn{7}{|l|}{ Presentation } \\
\hline Asymptomatic & 60 & 10 & $\begin{array}{l}\chi^{2}=2.371 \\
\Phi=0.082 \\
p=0.124\end{array}$ & 21 & 52 & \multirow[t]{2}{*}{$\begin{array}{l}\chi^{2}=0.089 \\
\Phi=0.015 \\
p=0.766\end{array}$} \\
\hline Symptomatic & 222 & 65 & & 83 & 224 & \\
\hline \multicolumn{7}{|c|}{ Time with symptoms } \\
\hline$<6$ months & 182 & 56 & $\begin{array}{l}\chi^{2}=0.618 \\
\Phi=-0.046 \\
p=0.432\end{array}$ & 71 & 185 & \multirow[t]{2}{*}{$\begin{array}{l}\chi^{2}=0.381 \\
\Phi=0.035 \\
p=0.537\end{array}$} \\
\hline$>6$ months & 40 & 9 & & 12 & 39 & \\
\hline \multicolumn{7}{|l|}{ Location } \\
\hline Colon & 196 & 86 & $\begin{array}{l}\chi^{2}=6.251 \\
\Phi=-0.132 \\
p=0.012\end{array}$ & 76 & 199 & \multirow[t]{2}{*}{$\begin{array}{l}\chi^{2}=0.036 \\
\Phi=0.010 \\
p=0.850\end{array}$} \\
\hline Rectum & 63 & 12 & & 28 & 77 & \\
\hline \multicolumn{7}{|c|}{ Macroscopic appearance } \\
\hline Polypoid & 154 & 33 & $\begin{array}{l}\chi^{2}=1.677 \\
V=0.071 \\
p=0.624\end{array}$ & 54 & 147 & \multirow[t]{4}{*}{$\begin{array}{l}\chi^{2}=0.585 \\
V=0.041 \\
p=0.900\end{array}$} \\
\hline Ulcerated & 74 & 15 & & 27 & 68 & \\
\hline Infiltrative & 22 & 8 & & 10 & 21 & \\
\hline Exophytic & 21 & 4 & & 6 & 19 & \\
\hline \multicolumn{7}{|c|}{ Carcinoembryonic antigen $(\mathrm{ng} / \mathrm{ml})$} \\
\hline$\leq 10$ & 220 & 27 & $\begin{array}{l}\chi^{2}=7.041 \\
\Phi=0.152 \\
p=0.008\end{array}$ & 88 & 191 & \multirow[t]{2}{*}{$\begin{array}{l}\chi^{2}=5.576 \\
\Phi=0.132 \\
p=0.018\end{array}$} \\
\hline$>10$ & 44 & 14 & & 6 & 37 & \\
\hline \multicolumn{7}{|l|}{ Tumor size $(\mathrm{cm})$} \\
\hline$\leq 4.5$ & 170 & 102 & $\begin{array}{l}\chi^{2}=1.356 \\
\Phi=0.063 \\
p=0.244\end{array}$ & 66 & 162 & $\begin{array}{l}\chi^{2}=1.752 \\
\Phi=0.069 \\
p=0.186\end{array}$ \\
\hline
\end{tabular}


Table 4 (Continued)

\begin{tabular}{|c|c|c|c|c|c|c|}
\hline & \multicolumn{3}{|c|}{ Preoperative NLR } & \multicolumn{3}{|c|}{ Postoperative NLR } \\
\hline & $\leq 5$ & $>5$ & Statistics & $\leq 5$ & $>5$ & Statistics \\
\hline$>4.5$ & 39 & 32 & & 31 & 106 & \\
\hline \multicolumn{7}{|l|}{ Histological type } \\
\hline Adenocarcinoma & 250 & 65 & $p=0.818$ & 97 & 239 & \multirow[t]{3}{*}{$p=0.157$} \\
\hline Mucinous adenocarcinoma & 30 & 9 & & 7 & 34 & \\
\hline Signet-ring cell adenocarcinoma & 2 & 1 & & 0 & 3 & \\
\hline \multicolumn{7}{|l|}{ Stage } \\
\hline $\mathrm{I}$ & 63 & 8 & $\begin{array}{l}\chi^{2}=8.823 \\
V=0.157 \\
p=0.012\end{array}$ & 17 & 59 & \multirow[t]{3}{*}{$\begin{array}{l}\chi^{2}=2.717 \\
V=0.085 \\
p=0.257\end{array}$} \\
\hline II & 120 & 28 & & 41 & 119 & \\
\hline III & 99 & 39 & & 46 & 98 & \\
\hline
\end{tabular}

Abbreviations: NLR, Neutrophil-to-lymphocyte ratio; V, Cramer V; $\Phi$, Phi coefficient; $\chi^{2}$, Chi-squared.

Also, patients with increased NLR in the postoperative period had a lower survival than patients with normal NLR (average survival of 132 months and 112 months respectively; $\mathrm{p}=0.002$ ), as shown in - Figure $\mathbf{3 B}$ and - Table 7.

The application of the GPS did not show significant differences between patients who scored 0,1 or 2 on the scale, both in the pre- and postoperative periods $(p=0.092$ and 0.254 respectively), as shown in -Figures $\mathbf{4 A}$ and $\mathbf{4 B}$.

The value of the isolated CRP was only used in the preoperative period, since, in the postoperative period, only one patient had values within normal limits. However, the increase in preoperative CRP showed a statistically significant decrease in patient survival $(\mathrm{p}=0.038)$, which is illustrated in - Figure $\mathbf{5}$.

\section{Evaluation of Disease-Free Time}

Similarly, the time from surgery to the occurrence of local and distant recurrences of the disease was also evaluated, using the comparison of the Kaplan-Meier curves of the patients according to the different scales.

The evaluation and comparison of the curves showed significant differences in disease-free time in patients with increased NLR in the preoperative period compared to patients with normal NLR (88.0 months and 123 months respectively; $\mathrm{p}<0.001$ ), as shown in -Figure $\mathbf{6 A}$ and - Table 8 . In the postoperative period, these differences were also noticeable (132 months if normal NLR, and 111 months if increased NLR; $p=0.002$ ), as shown in - Figure 6 B and - Table 8.

The application of the GPS did not show significant differences at any time with regard to the time until recurrence ( $p=0.083$ and 0.538 respectively), as shown in - Figures 7A and $\mathbf{7 B}$.

In this case, it was only possible to evaluate the CRP in the preoperative period, which showed a tendency towards significance between the two groups $(\mathrm{p}=0.059)$, as shown in -Figure 8.

\section{Uni- and Multivariate Analysis of the Impact on Cancer-Related Survival}

In order to determine the impact of each variable on the cancer-related survival of the patients, a univariate analysis was performed according to the Cox regression model. Then, using the variables that showed statistical significance in the univariate analysis, a multivariate analysis was carried out in order to determine which variables influenced the survival time independently of the others, as shown in - Table 9 .

An observation of the univariate analysis in -Table 9 enables us to conclude that the risk of death from CRC among patients with levels of CEA greater than $10 \mathrm{ng} / \mathrm{ml}$ is 2.21 times higher than that of patients with normal CEA levels (unadjusted hazard ratio $[\mathrm{HR}]=2.21 ; \mathrm{p}=0.002$ ). In addition, the risk of dying due to CRC among patients in stage II is 3.02 times higher than that of patients in stage I (unadjusted $H R=3.02$; $\mathrm{p}=0.007$ ). In turn, stage-III patients have a 6.06-fold higher risk (unadjusted $\mathrm{HR}=6.06 ; \mathrm{p}<0.001$ ). The univariate analysis of the impact of inflammatory markers on CRC-related survival confirms what had already been verified in the analysis of survival curves. The increase in the NLR in the preoperative period is associated with a 2.25 -fold increased risk of death from CRC (unadjusted $H R=2.25 ; p<0.001$ ). In the postoperative period, the increase in this scale implies an increase of 2.18 in the risk (unadjusted $H R=2.18 ; p=0.003$ ).

The increase in the GPS in the pre- and postoperative periods was not associated with a statistically significant increase in the risk of death from CRC, as did the CRP score in the preoperative period.

The multivariate analysis enables the identification of the variables that influence the survival time related to CRC independently from the other variables. By observing the multivariate analysis in $\mathbf{-}$ Table 9 , we can conclude that patients in stages II (adjusted $\mathrm{HR}=3.37 ; \mathrm{p}=0.013$ ) and III (adjusted $\mathrm{HR}=6.71$; $\mathrm{p}<0.001$ ) present a risk of 3.37 times and 6.71 times higher of death from CRC respectively. Also, the increased postoperative NLR independently increases the risk of death from CRC by 2.66 times (adjusted $\mathrm{HR}=2.66$ and $\mathrm{p}=0.002$ ). 
Table 5 Analysis of interdependence between pre- and postoperative GPS and several clinico-pathological variables

\begin{tabular}{|c|c|c|c|c|c|c|}
\hline & \multicolumn{3}{|c|}{ Preoperative GPS } & \multicolumn{3}{|c|}{ Postoperative GPS } \\
\hline & 0 & $1 / 2$ & Statistics & 1 & 2 & Statistics \\
\hline \multicolumn{7}{|l|}{ Gender } \\
\hline Male & 4 & 49 & \multirow[t]{2}{*}{$p \leq 0.99$} & 9 & 37 & \multirow{2}{*}{$\begin{array}{l}\chi^{2}=0.016 \\
\Phi=-0.015 \\
p=0.900\end{array}$} \\
\hline Female & 1 & 13 & & 5 & 19 & \\
\hline \multicolumn{7}{|l|}{ Age (years) } \\
\hline$\leq 45$ & 0 & 2 & \multirow[t]{2}{*}{$p<0.99$} & 0 & 1 & \multirow[t]{2}{*}{$p \leq 0.99$} \\
\hline$>45$ & 5 & 60 & & 14 & 55 & \\
\hline \multicolumn{7}{|l|}{ Previous tumor } \\
\hline Yes & 1 & 4 & \multirow[t]{2}{*}{$p=0.330$} & 1 & 3 & \multirow[t]{2}{*}{$p \leq 0.99$} \\
\hline No & 4 & 58 & & 13 & 53 & \\
\hline \multicolumn{7}{|l|}{ Family history } \\
\hline Yes & 2 & 6 & \multirow[t]{2}{*}{$p=0.110$} & 5 & 4 & \multirow[t]{2}{*}{$p=\mathbf{0 . 0 1 0}$} \\
\hline No & 3 & 54 & & 8 & 51 & \\
\hline \multicolumn{7}{|l|}{ Presentation } \\
\hline Asymptomatic & 1 & 17 & \multirow[t]{2}{*}{$p \leq 0.99$} & 7 & 6 & \multirow{2}{*}{$\begin{array}{l}\chi^{2}=11.430 \\
\Phi=0.404 \\
p<0.001\end{array}$} \\
\hline Symptomatic & 4 & 45 & & 7 & 50 & \\
\hline \multicolumn{7}{|l|}{ Time with symptoms } \\
\hline$<6$ months & 3 & 33 & \multirow[t]{2}{*}{$p \leq 0.99$} & 6 & 41 & \multirow[t]{2}{*}{$p \leq 0.99$} \\
\hline$>6$ months & 1 & 12 & & 1 & 9 & \\
\hline \multicolumn{7}{|l|}{ Location } \\
\hline Colon & 2 & 50 & \multirow[t]{2}{*}{$p=0.070$} & 11 & 39 & \multirow[t]{2}{*}{$p=0.742$} \\
\hline Rectum & 3 & 12 & & 3 & 17 & \\
\hline \multicolumn{7}{|l|}{ Macroscopic appearance } \\
\hline Polypoid & 2 & 35 & \multirow[t]{4}{*}{$p=0.369$} & 10 & 25 & $p=0.315$ \\
\hline Ulcerated & 3 & 15 & & 2 & 18 & \\
\hline Infiltrative & 0 & 5 & & 0 & 4 & \\
\hline Exophytic & 0 & 5 & & 1 & 6 & \\
\hline Carcinoembryonic antigen (ng/ml) & & & & & & \\
\hline$\leq 10$ & 4 & 53 & $p \leq 0.99$ & 11 & 41 & $p \leq 0.99$ \\
\hline$>10$ & 0 & 6 & & 2 & 6 & \\
\hline Tumor size $(\mathrm{cm})$ & & & & & & \\
\hline$\leq 4.5$ & 5 & 36 & $p=0.148$ & 9 & 31 & $p=0.592$ \\
\hline$>4.5$ & 0 & 25 & & 5 & 24 & \\
\hline Histological type & & & & & & \\
\hline Adenocarcinoma & 4 & 54 & $p=0.526$ & 14 & 46 & $p=0.194$ \\
\hline Mucinous adenocarcinoma & 1 & 8 & & 0 & 10 & \\
\hline Signet-ring cells adenocarcinoma & - & - & & - & - & \\
\hline Stage & & & & & & \\
\hline $\mathrm{I}$ & 3 & 7 & $p=0.017$ & 4 & 7 & $\chi^{2}=2.187$ \\
\hline II & 2 & 30 & & 5 & 25 & $\begin{array}{l}\Phi=0.1 / 1 \\
p=0.335\end{array}$ \\
\hline III & 0 & 25 & & 5 & 24 & \\
\hline
\end{tabular}

Abbreviations: GPS, Glasgow Prognostic Score; $\Phi$, Phi coefficient; $\chi^{2}$, Chi-squared. 
Table 6 Analysis of the interdependence between preoperative Creactive protein and several clinico-pathological variables

\begin{tabular}{|c|c|c|c|}
\hline & \multicolumn{3}{|c|}{ Preoperative C-reactive protein } \\
\hline & $\leq 1$ & $>1$ & Statistics \\
\hline \multicolumn{4}{|l|}{ Gender } \\
\hline Male & 7 & 65 & \multirow[t]{2}{*}{$p \leq 0.99$} \\
\hline Female & 2 & 25 & \\
\hline \multicolumn{4}{|l|}{ Age (years) } \\
\hline$\leq 45$ & 0 & 4 & \multirow[t]{2}{*}{$p \leq 0.99$} \\
\hline$>45$ & 9 & 86 & \\
\hline \multicolumn{4}{|l|}{ Previous tumor } \\
\hline Yes & 1 & 10 & \multirow[t]{2}{*}{$p \leq 0.99$} \\
\hline No & 8 & 80 & \\
\hline \multicolumn{4}{|l|}{ Family history } \\
\hline Yes & 1 & 8 & \multirow[t]{2}{*}{$p=0.568$} \\
\hline No & 7 & 78 & \\
\hline \multicolumn{4}{|l|}{ Presentation } \\
\hline Asymptomatic & 2 & 20 & \multirow[t]{2}{*}{$p \leq 0.99$} \\
\hline Symptomatic & 7 & 70 & \\
\hline \multicolumn{4}{|c|}{ Time with symptoms (months) } \\
\hline$<6$ & 6 & 56 & \multirow[t]{2}{*}{$p \leq 0.99$} \\
\hline$>6$ & 1 & 14 & \\
\hline \multicolumn{4}{|l|}{ Location } \\
\hline Colon & 4 & 74 & \multirow[t]{2}{*}{$p=\mathbf{0 . 0 1 9}$} \\
\hline Rectum & 5 & 16 & \\
\hline \multicolumn{4}{|c|}{ Macroscopic appearance } \\
\hline Polypoid & 4 & 48 & \multirow[t]{4}{*}{$p=0.087$} \\
\hline Ulcerated & 2 & 22 & \\
\hline Infiltrative & 3 & 6 & \\
\hline Exophytic & 0 & 6 & \\
\hline \multicolumn{4}{|c|}{ Carcinoembryonic antigen (ng/ml) } \\
\hline$\leq 10$ & 7 & 70 & \multirow[t]{2}{*}{$p \leq 0.99$} \\
\hline$>10$ & 0 & 8 & \\
\hline \multicolumn{4}{|l|}{ Tumor size } \\
\hline$\leq 4.5 \mathrm{~cm}$ & 9 & 55 & \multirow[t]{2}{*}{$p=\mathbf{0 . 0 2 6}$} \\
\hline$>4.5 \mathrm{~cm}$ & 0 & 33 & \\
\hline \multicolumn{4}{|l|}{ Histological type } \\
\hline Adenocarcinoma & 8 & 79 & \multirow[t]{3}{*}{$p \leq 0.99$} \\
\hline $\begin{array}{l}\text { Mucinous } \\
\text { adenocarcinoma }\end{array}$ & 1 & 11 & \\
\hline $\begin{array}{l}\text { Signet-ring cell } \\
\text { adenocarcinoma }\end{array}$ & Not available & Not available & \\
\hline \multicolumn{4}{|l|}{ Stage } \\
\hline $\mathrm{I}$ & 3 & 12 & \multirow[t]{3}{*}{$p=0.234$} \\
\hline II & 4 & 41 & \\
\hline III & 2 & 37 & \\
\hline
\end{tabular}

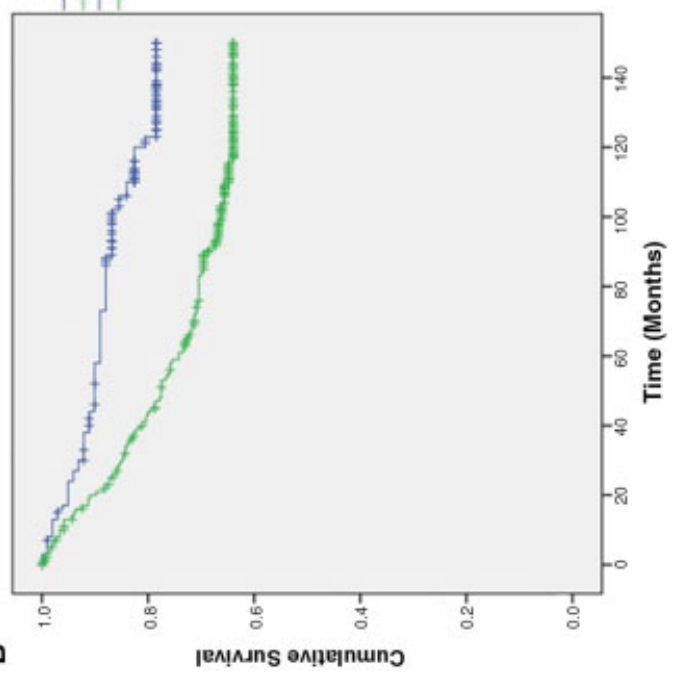

m

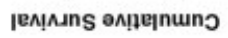

Note: The value of the isolated CRP was only used in the preoperative period, since, in the postoperative period, only 1 patient had normal values.

The levels of CEA and the value of the preoperative NLR do
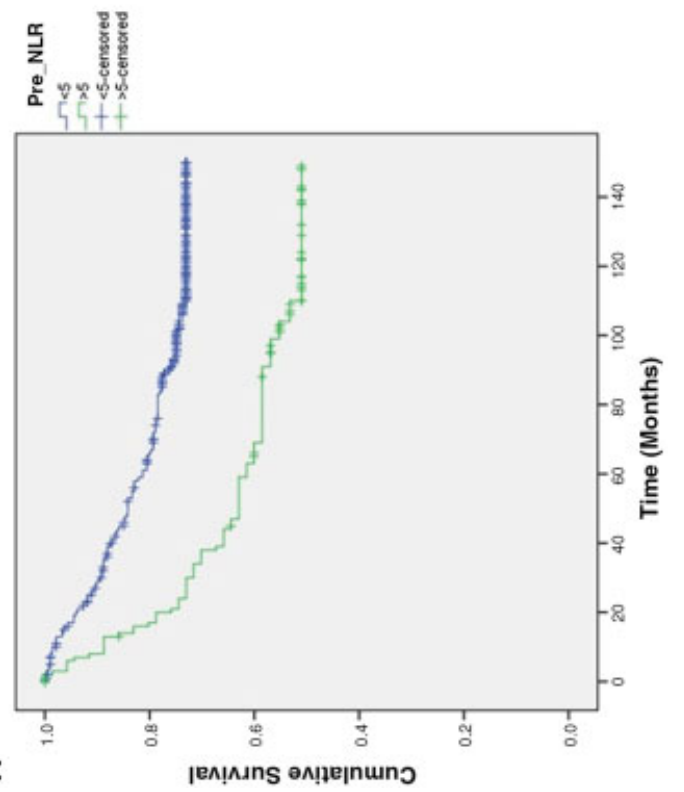
not significantly increase the risk of death from CRC independently of the other variables. 
Table 7 Average cancer-related survival time according to NLR in the preoperative and postoperative periods

\begin{tabular}{|c|c|c|c|c|}
\hline & \multicolumn{4}{|l|}{ Average } \\
\hline & \multirow[t]{2}{*}{ Estimate } & \multirow[t]{2}{*}{ Standard error } & \multicolumn{2}{|c|}{$95 \%$ confidence interval } \\
\hline & & & Inferior limit & Superior limit \\
\hline \multicolumn{5}{|c|}{ Preoperative NLR } \\
\hline$<5$ & 122.248 & 3.009 & 116.350 & 128.145 \\
\hline$>5$ & 93.675 & 7.332 & 79.305 & 108.045 \\
\hline Global & 116.401 & 2.900 & 110.717 & 122.086 \\
\hline \multicolumn{5}{|c|}{ Postoperative NLR } \\
\hline$<5$ & 131.792 & 4.100 & 123.757 & 139.827 \\
\hline$>5$ & 112.022 & 3.408 & 105.343 & 118.701 \\
\hline Global & 117.488 & 2.751 & 112.096 & 122.880 \\
\hline
\end{tabular}

Abbreviation: NLR, Neutrophil-to-lymphocyte ratio.

A

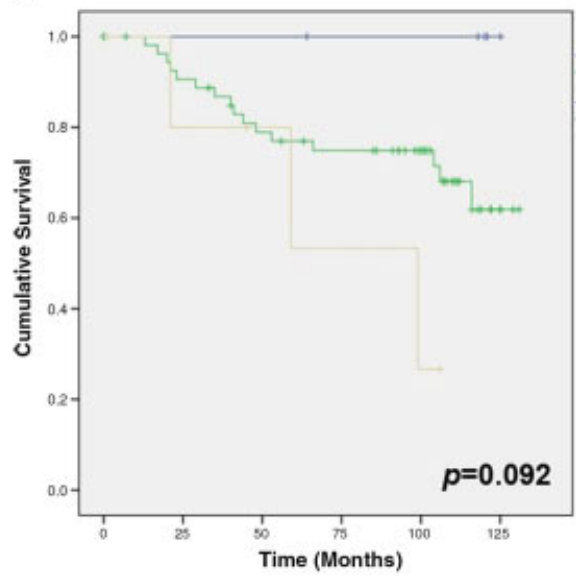

B

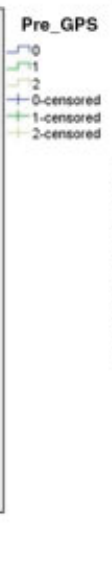

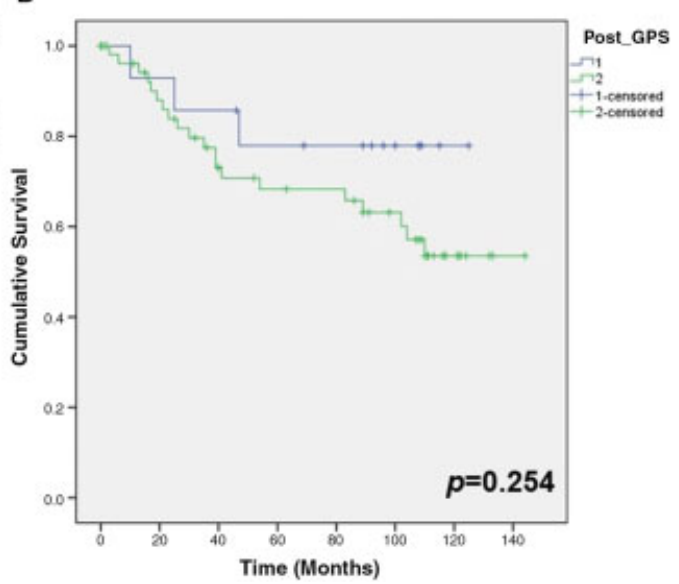

Fig. 4 Kaplan-Meier curves for survival according to the GPS in the preoperative (A) and postoperative (B) periods.

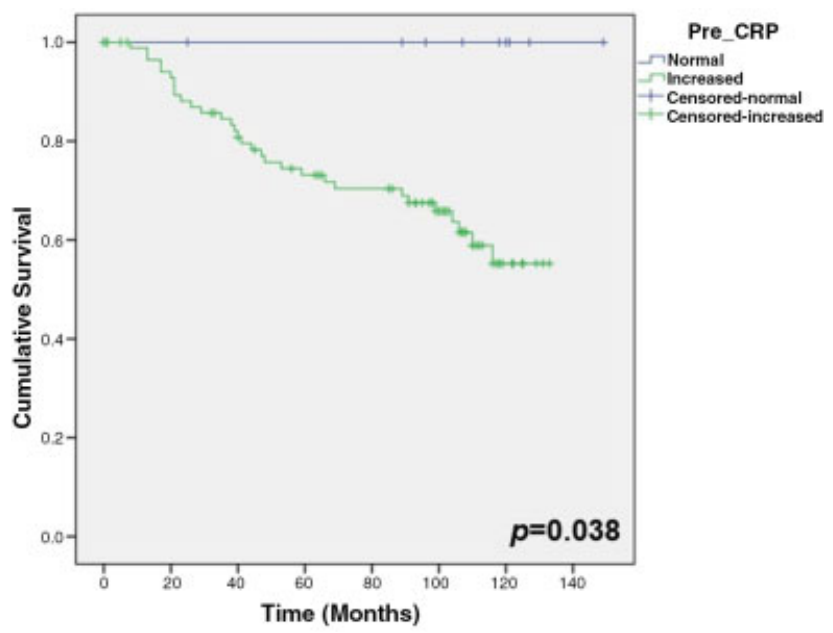

Fig. 5 Kaplan-Meier curve for survival according to CRP levels.

\section{Discussion}

Currently, staging is the main determinant of the prognosis of patients with CRC. ${ }^{1,12}$ Recently, the impact of the elevation of systemic inflammatory markers has gained increasing interest. Scales such as the GPS, the NLR and isolated CRP have been shown to influence the prognosis of various cancers, including CRC. ${ }^{2-7,11,13}$

The study sample, composed of 426 patients, showed a predominance of male individuals, which is in agreement with what is described in the literature. ${ }^{14}$ Moreover, the median age at diagnosis, 71.5 years, with $96.2 \%$ of the diagnoses occuring after the age of 45 years, is in accordance with the bibliographic data, which place age as one of the main non-modifiable risk factors for the development of CRC. ${ }^{1,13,15}$ Regarding the location of the tumor, there was a predominance of tumors located in the left colon (50.0\%), which is also in accordance with what is described in the literature. $^{16-18}$

Regarding the impact of the elevation of the different inflammatory markers on survival, we found that patients with increased NLR in the preoperative period $(\mathrm{p}<0.001)$ had a significantly lower survival rate than patients with normal NLR. The same was true for patients with increased NLR in the postoperative period ( $\mathrm{p}=0.002)$.

In addition, the increase in the preoperative levels of isolated CRP was associated with a significant decrease in patient survival $(\mathrm{p}=0.038)$. 
A

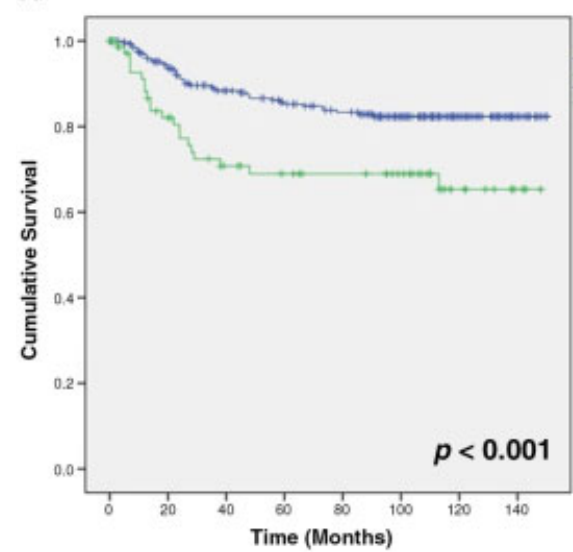

B

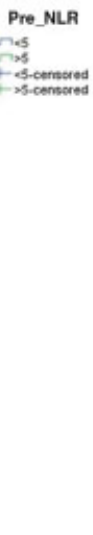

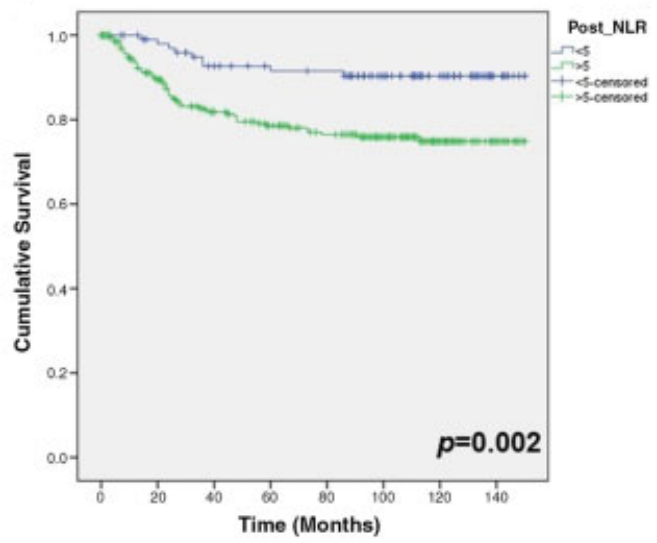

Fig. 6 Kaplan-Meier curves for disease-free survival according to the NLR in the preoperative (A) and postoperative (B) periods.

Table 8 Average disease-free time according to NLR in the preoperative and postoperative periods

\begin{tabular}{|c|c|c|c|c|}
\hline & \multicolumn{4}{|l|}{ Average } \\
\hline & \multirow[t]{2}{*}{ Estimate } & \multirow[t]{2}{*}{ Standard error } & \multicolumn{2}{|c|}{ 95\% confidence Interval } \\
\hline & & & Inferior limit & Superior limit \\
\hline \multicolumn{5}{|c|}{ Preoperative NLR } \\
\hline$<5$ & 122.710 & 3.201 & 116.436 & 128.984 \\
\hline$>5$ & 88.004 & 7.685 & 72.942 & 103.065 \\
\hline Global & 115.657 & 3.105 & 109.572 & 121.742 \\
\hline \multicolumn{5}{|c|}{ Postoperative NLR } \\
\hline$<5$ & 132.010 & 4.377 & 123.430 & 140.590 \\
\hline$>5$ & 110.784 & 3.720 & 103.493 & 118.075 \\
\hline Global & 116.977 & 2.973 & 111.150 & 122.805 \\
\hline
\end{tabular}

Abbreviation: NLR, Neutrophil-to-lymphocyte ratio.

A

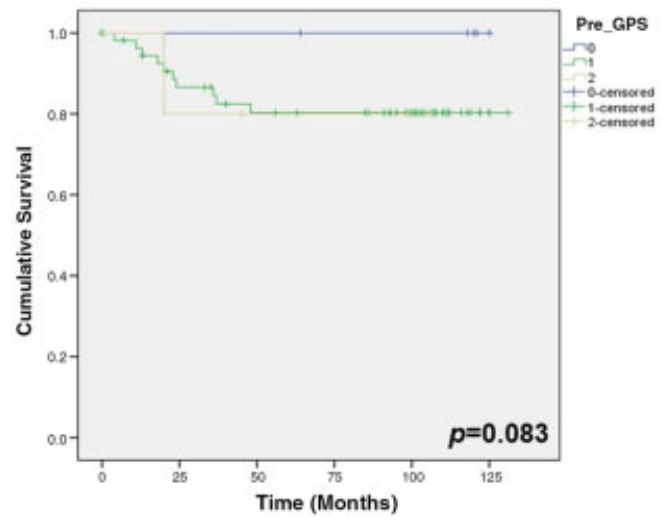

B

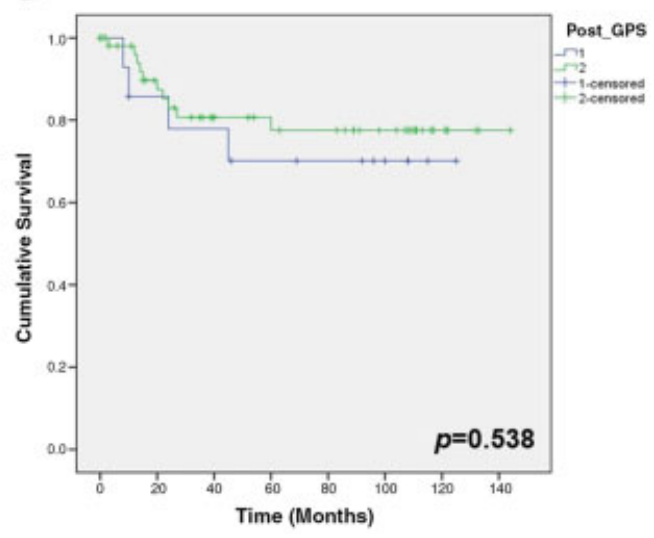

Fig. 7 Kaplan-Meier curves for disease-free survival according to the GPS in the preoperative (A) and postoperative (B) periods.

Regarding the GPS, no significant differences in survival were detected either in the preoperative period $(p=0.092)$ or in the postoperative period $(\mathrm{p}=0.254)$.

With regard to the local and distant recurrences of the disease, significant differences were detected in the diseasefree time in patients with increased NLR in the preoperative period compared to patients with normal NLR ( $\mathrm{p}<0.001)$. This was also observed in the postoperative period $(p=0.002)$. However, neither the application of the GPS (preoperatively: $\mathrm{p}=0.083$; postoperatively: $\mathrm{p}=0.538$ ), nor the isolated CRP ( $p=0.059$ in the preoperative period) showed significant differences in relation to recurrence. 


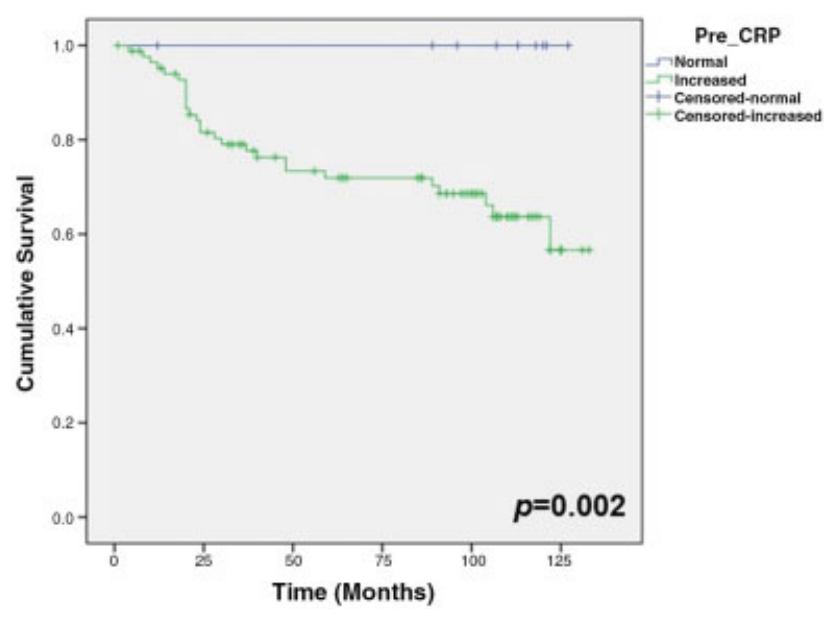

Fig. 8 Kaplan-Meier curve for disease-free survival according to CRP levels in the preoperative period.
The univariate analysis of the data showed that the increase in the levels of CEA (unadjusted $\mathrm{HR}=2.21$; $\mathrm{p}=0.002$ ), more advanced stages of the disease (stage II: unadjusted $\mathrm{HR}=3.02 ; \mathrm{p}=0.007$; stage III: unadjusted HR $=6.06 ; \mathrm{p}<0.001$ ), and an elevation of the NLR in the preoperative and postoperative periods (unadjusted $\mathrm{HR}=2.25$; $\mathrm{p}$ $<0.001$; unadjusted $\mathrm{HR}=2.18 ; \mathrm{p}=0.003$ respectively) are associated with a higher risk of death due to CRC.

The multivariate analysis, in turn, showed that, of these variables, only the advanced stage (stage II: adjusted HR =3.37; $\mathrm{p}=0.013$; stage III: adjusted HR $=6.71 ; \mathrm{p}<0.001$ ) and the postoperative NLR (adjusted HR=2.66; $\mathrm{p}=0.002$ ), increase the risk independently of the remaining variables.

The fact that the preoperative NLR did not show significant results in the multivariate analysis may be due to the existence of a correlation $(\mathrm{p}=0.012)$ between increased preoperative NLR and more advanced stages of the disease, which is not the case for postoperative NLR, as can be confirmed in - Table 4 .

Table 9 Univariate and multivariate analyses of the impact of different variables on the time of cancer-related survival of patients, according to the Cox regression model

\begin{tabular}{|c|c|c|c|c|c|c|}
\hline & \multicolumn{3}{|c|}{ Univariate analysis } & \multicolumn{3}{|c|}{ Multivariate analysis } \\
\hline & $\begin{array}{l}\text { Unadjusted } \\
\text { hazard ratio }\end{array}$ & $\begin{array}{l}\text { 95\% confidence } \\
\text { interval }\end{array}$ & p-value & $\begin{array}{l}\text { Adjusted hazard } \\
\text { ratio }\end{array}$ & $\begin{array}{l}95 \% \text { confidence } \\
\text { interval }\end{array}$ & $p$-value \\
\hline Gender (female) & 1.012 & $0.689-1.486$ & 0.953 & - & - & - \\
\hline Age (> 45 years) & 1.534 & $0.487-4.830$ & 0.465 & - & - & - \\
\hline Previous tumor (yes) & 0.937 & $0.535-1.640$ & 0.818 & - & - & - \\
\hline Family history (yes) & 0.507 & $0.222-1.158$ & 0.107 & - & - & - \\
\hline $\begin{array}{l}\text { Presentation } \\
\text { (symptomatic) }\end{array}$ & 1.220 & $0.752-1.978$ & 0.421 & - & - & - \\
\hline $\begin{array}{l}\text { Time with symptoms (> } \\
6 \text { months) }\end{array}$ & 0.757 & $0.412-1.388$ & 0.368 & - & - & - \\
\hline Location (Rectum) & 1.047 & $0.695-1.578$ & 0.826 & - & - & - \\
\hline \multicolumn{4}{|l|}{ Macroscopic appearance } & \multirow[t]{4}{*}{-} & \multirow[t]{4}{*}{-} & \multirow[t]{4}{*}{-} \\
\hline Polypoid & 0.877 & $0.376-2.044$ & 0.761 & & & \\
\hline Ulcerated & 1.070 & $0.445-2.572$ & 0.880 & & & \\
\hline Infiltrative & 1.527 & $0.580-4.019$ & 0.391 & & & \\
\hline $\begin{array}{l}\text { Carcinoembryonic anti- } \\
\text { gen }(>10)\end{array}$ & 2.206 & $1.334-3.647$ & 0.002 & 1.707 & $0.986-2.954$ & 0.056 \\
\hline Tumor size $(>4.5 \mathrm{~cm})$ & 1.116 & $0.757-1.645$ & 0.580 & - & - & - \\
\hline $\begin{array}{l}\text { Histological type } \\
\text { (mucinous) }\end{array}$ & 1.374 & $0.770-2.452$ & 0.283 & - & - & - \\
\hline \multicolumn{7}{|l|}{ Stage } \\
\hline II & 3.018 & $1.357-6.710$ & 0.007 & 3.367 & $1.299-8.729$ & 0.013 \\
\hline III & 6.064 & $2.774-13.257$ & $<0.001$ & 6.706 & $2.630-17.102$ & $<0.001$ \\
\hline Preoperative NLR (> 5) & 2.252 & $1.484-3.418$ & $<0.001$ & 1.509 & $0.902-2.523$ & 0.117 \\
\hline Postoperative NLR (>5) & 2.178 & $1.310-3.621$ & 0.003 & 2.656 & $1.412-4.998$ & 0.002 \\
\hline Preoperative GPS ( 1 or 2 ) & 2.47 & $0.042-8.028$ & 0.352 & - & - & - \\
\hline Postoperative GPS (2) & 2.000 & $0.593-6.474$ & 0.264 & - & - & - \\
\hline $\begin{array}{l}\text { Preoperative CRP (> } \\
1 \mathrm{mg} / \mathrm{dl} \text { ) }\end{array}$ & 2.481 & $0.217-2.841$ & 0.184 & - & - & - \\
\hline
\end{tabular}

Abbreviations: GPS, Glasgow Prognostic Score; CRP, C-reative protein; NLR, Neutrophil-to-lymphocyte ratio. 
Thus, we can conclude that, in the study sample, the NLR would be the scale whose results most consistently influenced the patients' prognosis, regarding cancer-related survival and the time to relapse of the disease. However, only the postoperative NLR of the scales under analysis influences the prognosis independently of the remaining variables.

This conclusion can be supported by the understanding of the pathophysiological mechanisms in which these immune cells are involved, since the increase in the number of neutrophils has been associated with tumor progression, by the creation of cytokines that induce tumor growth, as well as by the creation of an proangiogenic environment, favorable to vascularization and tumor invasion. ${ }^{19-21}$ In contrast, lymphocytes play a primarily antitumor role, and their increase reflects the activation of the patient's immune system. $^{22-25}$

The first study to demonstrate a direct relationship between elevated inflammatory markers and decreased survival in patients with CRC was carried out in 2007 by McMillan et al., ${ }^{26}$ who showed that an increase in the preoperative GPS was associated with a shorter survival.

In 2012, Sugimoto et al. ${ }^{3}$ also demonstrated that an increased GPS was related to decreased survival, as did Guthrie et al., ${ }^{27}$ who, in 2013, obtained similar results. The latter study even concluded that the GPS was a scale superior to the NLR in assessing the impact on survival.

There are several studies demonstrating the association between patients and an increase in the preoperative inflammatory parameters; however, few are related to the postoperative period. Nevertheless, in 2015, Shibutani et al. ${ }^{28}$ concluded that an elevated NLR both in the preoperative and postoperative periods correlated with a decrease in patient survival.

More recently, Rosi et al. ${ }^{29}$ demonstrated that the GPS and the NLR are superior to other markers in assessing the survival of patients with CRC.

Much less frequent are the studies relating the increase in inflammatory parameters with the recurrence of the disease. However, in 2017, Balde et al. $^{30}$ demonstrated that an increase in the preoperative NLR is a strong predictor of shorter survival time without recurrence.

The present study has some limitations. The fact that this is a retrospective study makes it difficult to collect the data, and to ensure the homogeneity of the records. In addition, some patients were lost to follow-up. Regarding the comparison of the scales, there was less data available for the GPS and CRP than for the NLR, which may help to justify the fact that the former two did not show significant results.

\section{Conclusion}

Inflammatory markers have been increasingly associated with the prognosis of different neoplasias, namely CRC. The present study demonstrated an association between pre- and postoperative NLR and the survival and recurrence of patients with CRC. In addition, it showed that the postoperative NLR influences CRC mortality independently of the remaining variables.
These markers are routinely requested in the preoperative exams of patients, so they are accessible and do not represent an additional cost; therefore, their implementation in clinical practice is simple and will enable an assessment of additional surgical risk as well as the prognosis of the patient.

\section{Conflict of Interests}

The authors have no conflict of interests to declare.

\section{References}

1 Chua TC, Saxena A, Chu F, Zhao J, Morris DL. Predictors of cure after hepatic resection of colorectal liver metastases: an analysis of actual 5- and 10-year survivors. J Surg Oncol 2011;103(08): 796-800

2 Maeda K, Shibutani M, Otani H, et al. Prognostic value of preoperative inflammation-based prognostic scores in patients with stage IV colorectal cancer who undergo palliative resection of asymptomatic primary tumors. Anticancer Res 2013;33(12):5567-5573

3 Sugimoto K, Komiyama H, Kojima Y, Goto M, Tomiki Y, Sakamoto K. Glasgow prognostic score as a prognostic factor in patients undergoing curative surgery for colorectal cancer. Dig Surg 2012; 29(06):503-509

4 Ishizuka M, Nagata H, Takagi K, Horie T, Kubota K. Inflammationbased prognostic score is a novel predictor of postoperative outcome in patients with colorectal cancer. Ann Surg 2007;246 (06):1047-1051

5 Shibutani M, Maeda K, Nagahara H, et al. A high preoperative neutrophil-to-lymphocyte ratio is associated with poor survival in patients with colorectal cancer. Anticancer Res 2013;33(08): 3291-3294

6 Chiang SF, Hung HY, Tang R, et al. Can neutrophil-to-lymphocyte ratio predict the survival of colorectal cancer patients who have received curative surgery electively? Int J Colorectal Dis 2012;27 (10):1347-1357

7 Chung YC, Chang YF. Serum C-reactive protein correlates with survival in colorectal cancer patients but is not an independent prognostic indicator. Eur J Gastroenterol Hepatol 2003;15(04):369-373

8 Wu J, Cai Q, Li H, et al. Abstract 102: Circulating C-reactive protein and colorectal cancer risk: a report from the Shanghai Men's Health Study. Cancer Res 2013;73(8, Supplement):102-102

9 Zhang P, Xi M, Li QQ, et al. The modified glasgow prognostic score is an independent prognostic factor in patients with inoperable thoracic esophageal squamous cell carcinoma undergoing chemoradiotherapy. J Cancer 2014;5(08):689-695

10 Gürağaç A, Demirer Z. The neutrophil-to-lymphocyte ratio in clinical practice. Can Urol Assoc J 2016;10(3-4):141

11 Urrejola GI, Bambs CE, Espinoza MA, et al. [An elevated neutrophil/lymphocyte ratio is associated with poor prognosis in stage II resected colon cancer]. Rev Med Chil 2013;141(05):602-608

12 Gloeckler Ries LA, Reichman ME, Lewis DR, Hankey BF, Edwards BK. Cancer survival and incidence from the Surveillance, Epidemiology, and End Results (SEER) program. Oncologist 2003;8(06):541-552

13 Hassan C, Gimeno-García A, Kalager M, et al. Systematic review with meta-analysis: the incidence of advanced neoplasia after polypectomy in patients with and without low-risk adenomas. Aliment Pharmacol Ther 2014;39(09):905-912

14 Ferlay J, Soerjomataram I, Dikshit R, et al. Cancer incidence and mortality worldwide: sources, methods and major patterns in GLOBOCAN 2012. Int J Cancer 2015;136(05):E359-E386

15 Chen K, Qiu JL, Zhang Y, Zhao YW. Meta analysis of risk factors for colorectal cancer. World J Gastroenterol 2003;9(07):1598-1600

16 Lieberman DA, Prindiville S, Weiss DG, Willett WVA Cooperative Study Group 380. Risk factors for advanced colonic neoplasia and hyperplastic polyps in asymptomatic individuals. JAMA 2003;290 (22):2959-2967 
17 Tarver T. Cancer Facts \& Figures 2017. American Cancer Society (ACS). J Consum Health Internet 2017;16(03):366-367

18 Hemminki K, Santi I, Weires M, Thomsen H, Sundquist J, Bermejo JL. Tumor location and patient characteristics of colon and rectal adenocarcinomas in relation to survival and TNM classes. BMC Cancer 2010;10(01):688

19 Neal CP, Mann CD, Sutton CD, et al. Evaluation of the prognostic value of systemic inflammation and socioeconomic deprivation in patients with resectable colorectal liver metastases. Eur J Cancer 2009;45(01):56-64

20 Terzić J, Grivennikov S, Karin E, Karin M. Inflammation and colon cancer. Gastroenterology 2010;138(06):2101-2114.e5

21 Nozawa H, Chiu C, Hanahan D. Infiltrating neutrophils mediate the initial angiogenic switch in a mouse model of multistage carcinogenesis. Proc Natl Acad Sci U S A 2006;103(33):12493-12498

22 Kitayama J, Yasuda K, Kawai K, Sunami E, Nagawa H. Circulating lymphocyte is an important determinant of the effectiveness of preoperative radiotherapy in advanced rectal cancer. BMC Cancer 2011;11(01):64

23 Okano K, Maeba T, Moroguchi A, et al. Lymphocytic infiltration surrounding liver metastases from colorectal cancer. J Surg Oncol 2003;82(01):28-33

24 Chiba T, Ohtani H, Mizoi T, et al. Intraepithelial CD8+ T-cellcount becomes a prognostic factor after a longer follow-up period in human colorectal carcinoma: possible association with suppression of micrometastasis. Br J Cancer 2004;91(09): 1711-1717

25 Erdman SE, Sohn JJ, Rao VP, et al. CD4+CD25+ regulatory lymphocytes induce regression of intestinal tumors in ApcMin/+ mice. Cancer Res 2005;65(10):3998-4004

26 McMillan DC, Crozier JE, Canna K, Angerson WJ, McArdle CS. Evaluation of an inflammation-based prognostic score (GPS) in patients undergoing resection for colon and rectal cancer. Int J Colorectal Dis 2007;22(08):881-886

27 Guthrie GJ, Roxburgh CS, Farhan-Alanie OM, Horgan PG, McMillan DC. Comparison of the prognostic value of longitudinal measurements of systemic inflammation in patients undergoing curative resection of colorectal cancer. $\mathrm{Br} \mathrm{J}$ Cancer 2013;109(01):24-28

28 Shibutani M, Maeda K, Nagahara $\mathrm{H}$, et al. The prognostic significance of a postoperative systemic inflammatory response in patients with colorectal cancer. World J Surg Oncol 2015;13(01):194

29 Rossi S, Basso M, Strippoli A, et al. Are Markers of Systemic Inflammation Good Prognostic Indicators in Colorectal Cancer? Clin Colorectal Cancer 2017;16(04):264-274

30 Balde AI, Fang S, He L, et al. Propensity score analysis of recurrence for neutrophil-to-lymphocyte ratio in colorectal cancer. J Surg Res 2017;219:244-252 